\title{
Third-year Vet Med Students' Speaking Performance in English: Evaluation and Suggestions
}

\author{
Larice Toko Lumanda \\ Department of English Letters and Civilization, University of Kinshasa, Kinshasa, Democratic Republic of Congo \\ Email address: \\ lumanda08@gmail.com \\ To cite this article: \\ Larice Toko Lumanda. Third-year Vet Med Students' Speaking Performance in English: Evaluation and Suggestions. Communication and \\ Linguistics Studies. Vol. 5, No. 3, 2019, pp. 65-73. doi: 10.11648/j.cls.20190503.12
}

Received: August 12, 2019; Accepted: August 30, 2019; Published: September 17, 2019

\begin{abstract}
The ascertainment of the Third-Year Vet Students' poverty to perform in oral English has been noticed in the Veterinary Medicine Department at the University of Kinshasa. People join universities and colleges in order to acquire sufficient knowledge that makes them capable of working in different areas of life. The Third-Year Students in Veterinary Medicine Department need a good command of English for both their academic activities (for the present moment) and job requirements (for the future). Unfortunately, the reality is that these students are less proficient in oral English than they are expected to be. Considering their poor performance, this article aims at evaluating the Third-Year Students' performance in oral English so as to suggest recommendations for successful speaking performance. To collect and analyze data, qualitative and quantitative methods are used. As far as the qualitative methods are concerned, this article applies the Capstone Project or Course, Syllabus Review, Observation, SWOT Analysis, and Course Evaluation Survey. Capstone Project is used to evaluate the students' knowledge, abilities, and concepts they have required from the first year up to the third one. Syllabus Review Method is used to examine both the teaching objectives and outcomes so as to make sure whether the students have reached the expected performance or not. Observations Methods is used to examine the students' behaviors and their environment in which the learning took place. SWOT Analysis is used to examine how the course content matches academic and occupational purposes. Course Evaluation Survey is used to point out the students' perception of the English course. Apart from the qualitative methods, the quantitative methods used in this paper are Certification, Exit Exam, and Performance. Certification Method is useful in evaluation of the students' general knowledge of English used in the veterinary medicine field. Exit Exam is employed in this paper to realize how much the students are able to apply their English knowledge in their life. Performance Method is used to evaluate the students' ability to give presentations as it is required. The results of the analysis of data and the related interpretation prove that the Third-Year Students are not performant in oral English because of the reasons listed in this paper. Furthermore, the conclusion of the interpretation suggests recommendations so as to cure the problem related to the lack of speaking performance in the Third-Year Students.
\end{abstract}

Keywords: Speaking Performance, Evaluation, Students' Needs, Teaching Process, Debates, Presentations

\section{Introduction}

The ascertainment shows that the Third-Year Students (in the Veterinary Medicine Department at the University of Kinshasa) are less proficient in oral English than they are expected to be after they have learnt English for three years. One of the main roles of a University lecturer is to reach the course objectives. In this case, the course objective is to enable students to speak English related to the field of veterinary medicine. The poverty of the Third-Year Students' speaking performance in English shows that the teaching objectives were not met. This is a serious problem that needs an investigation. Therefore, there is an emergency to evaluate the Third-Year Students' speaking performance in the Veterinary Medicine Department at the University of Kinshasa.

Considering the students' poor performance, this article aims at evaluating the Third-Year Students' speaking performance in oral English so as to detect the main causes of the lack of speaking performance in the Third-Year Students and find out the way to solve such a problem.

This paper discusses the concepts evaluation and 
performance before it presents the results from the questionnaire, test, and the observation of the teaching process. The interpretation of these results leads to the suggestions.

\section{Evaluation}

Desheng and Varghese [6] define evaluation as "the comparison of actual (project) impacts against the agreed strategic plans. It looks at the original objectives, at what was accomplished, and how it was accomplished". Desheng and Varghese consider evaluation as a comparison. This definition seems not to be exhaustive since the focus is only on opposing impacts against the agreed plan. For a clear understanding, evaluation can be defined as a systematic study that aims at measuring an expected achievement after a given activity. It is a systematic study because it has its methods and techniques. Its objective is the measurement of the expected achievement. That is to say, the objective of evaluation is to measure the level of results in order to know whether they are satisfactory or not. It is because of this reason that evaluation is and must be used in different fields such as Teaching/Learning, business, economics, etc.

\subsection{Types of Language Evaluation}

There are numeral types of language evaluation. This section discusses the common types of evaluation namely Formative Evaluation, Summative Evaluation, Process Evaluation, Outcomes Evaluation, and impact evaluation. I discuss each of them in the perspective of the objectives of this work.

\subsubsection{Formative Evaluation}

Generally speaking, the formative evaluation is the evaluation of the teaching program in order to improve it. Boothroyd [3] explains formative evaluation as follows.

Formative Evaluation-involves gathering information during early stage of program implementation or when programs have undertaken major redesigns, with a focus on finding out whether your efforts are unfolding as planned, uncovering any obstacles, barriers or unexpected opportunities that may have emerged, and identifying midcourse adjustments and corrections which can help insure the program's success.

As far as this paper is concerned, Formative Evaluation is used to evaluate the course contents taught to students from the first year up to the third one so as to make sure whether the contents match the expectations of the teaching of English in the Veterinary Medicine Department.

\subsubsection{Summative Evaluation}

The summative evaluation focuses on the effectiveness of the program so as to decide its continuity, end, and expansion. Boothroyd [3] clarifies summative evaluation in this way.

Summative Evaluation-involves gathering information once programs have been fully implemented (usually at the end of an operating cycle), to assess the impact and outcomes of the program to help make decisions about whether the program should be adopted, continued, or modified for improvement.

The summative evaluation, which is applied in this paper, focuses on how much effective the English course is in the Veterinary Medicine Department in order to suggest whether it can continue to be taught in the same way or not.

\subsubsection{Process Evaluation}

The process Evaluation focuses on the strategies of the program implementation in order to provide explanation about the change occurred in the program. Boothroyd [3] argues that

Process Evaluation -allows an organization to examine how it develops its structures and its programs in order to attain the outcomes everyone wants it to achieve. In other words, process evaluation documents the process of a program's implementation. Process evaluations help stakeholders see how a program outcomes or impacts are (or will be) achieved. The focus of a process evaluation is on the types and quantities of services delivered, the beneficiaries of those services, there sources used to deliver the services, the practical problems encountered, and the ways such problems were resolved.

For a teaching objective to be attained, the course should be taught effectively. Therefore, the process evaluation is done in order to examine how the course is taught and how the objectives are attained.

\subsubsection{Outcome Evaluation}

The outcome evaluation indicates how the teaching program has created a change in the learners. In other words, Boothroyd [3] stipulates that

Outcome Evaluation assesses the effectiveness of a program in producing change. Outcome evaluations (or impact evaluations) focus on the questions that ask what happened to program participants and how much of a difference the program made for them. Impact or outcome evaluations are undertaken when one wants to assess whether and how well the objectives of a program were met.

The role of the outcome evaluation in this paper is to evaluate the Third-Year Students' speaking performance in English. That is to say, how much performant these students have become after three years of training in English.

\subsubsection{Impact Evaluation}

An impact evaluation focuses on the effects or consequences resulted from the results of teaching program. Gertler, P. J. et al. [7] say it in another way

Impact evaluations are a particular type of evaluation that seeks to answer a specific cause-and-effect question: What is the impact (or causal effect) of a program on an outcome of interest? This basic question incorporates an important causal dimension. The focus is only on the impact: that is, the changes directly attributable to a program, program modality, or design innovation. 
After the Third-Year Students' speaking performance has been evaluated, the impact evaluation is conducted in order to point out the impact of such performance on the teaching objectives and students' expectations.

\subsection{Language Evaluation Qualities}

Evaluation can be well or badly done. When it is badly done, the consequence is that the study does not bring any good contribution to the improvement of the teaching program, teaching objectives, teaching methods and techniques or strategies, etc. Therefore, a discussion of evaluation qualities is of paramount importance. The following lines present the evaluation qualities.

\subsubsection{Validity}

An evaluation is valid when it evaluates only what is expected to be evaluated. As Ghazali [8] illustrates that "an instrument is valid when it is measuring what is supposed to measure". Validity can also be understood in terms of sensitivity and specificity. As far as this article is concerned, the former focuses on the students who have high performance whereas the latter deals with students having low performance.

\subsubsection{Reliability}

The reliability of an evaluation is based on appropriate methods that allow collecting and analyzing data consistently so as to have the same results whenever the evaluation is repeated. Peersman [10] argues that "Reliability: Data are measured and collected consistently according to standard definitions and methodologies; the results are the same when measurements are repeated". Cambridge English [4] adds that "reliability concerns the extent to which test results are stable, consistent and free from errors of measurement".

\subsubsection{Practicality}

Cambridge English [4] defines practicality as "the extent to which an examination is practicable in terms of the resources necessary to produce and administer it in its intended context and use". This is to say that evaluation must be adapted at the level of the stakeholders.

\subsubsection{Fairness}

Evaluation is fair when it is done in the same way for all evaluatees. It should not be influenced by anything or people. The evaluator should avoid any influence from evaluatees or other people who would not like to expect a negative viewpoint after the evaluation. Fairness also requires informing the evaluatees about what they are to be evaluated for, as Key [9] writes "fairness: evaluation must be fair to all students. This can be possible by accurate reflecting of range of expected behaviours as desired by the course objectives. To keep fairness in evaluation, it is also desired that students should know exactly how they are to be evaluated". The students' speaking performance evaluation which is the concern in this article must be done in the same way for all Third-year Students, and it should not be influenced either by the lecturer.

\subsubsection{Usefulness/Utility}

Evaluation should contribute to improve the language teaching and learning. Therefore, its objective must be the improvement of existing teaching program. Derbinski and Reinhardt [5] state that "an evaluation should address the objectives of the evaluation and the users' information requirements. Evaluation reports should contain all necessary information and should be easy to understand and comprehensible".

The usefulness of the evaluation of the Third-Year Students' speaking performance in English is the revelation of the level of the performance attained by these students.

\subsubsection{Credibility}

Credibility of an evaluation implies the one of the evaluator. For an evaluation to be credible, the evaluator must be as competent as possible in order to attain the valid and reliable results. Derbinski and Reinhardt [5] argue that "those conducting the evaluations should be methodologically and technically competent, impartial and independent in order to attain the optimum level of credibility and acceptance for the evaluation results".

\subsubsection{Precision}

As a scientific activity, evaluation should not produce confusing results i.e. the results should relate to the evaluatees. Derbinski and Reinhardt [5] say that

an evaluation should produce and communicate credible information and results relating to the evaluation object and questions of the evaluation. Key ways of guaranteeing this are: - to deploy adequate methodologies, - to take account of the perspective of all relevant stakeholders, - to collect sufficient data for a generally valid statement and appraisal to be made.

\subsection{Language Evaluation Processes}

Evaluation is not done in whatever manner. It has its specific procedure which must be followed in order to attain valid and reliable results. The evaluation procedure is based on a cycle of four phases namely planning, implementation, analysis and reporting, and action and improvement. The following lines discuss the four phases that constitute the evaluation cycle.

\subsubsection{Planning}

Planning is the first phase of evaluation cycle. It is the fact of designing a framework, determining objectives, appointing an evaluator, drawing up a budget, and constructing a plan.

i.) Designing a Framework

Before an evaluation is started, a framework needs to be designed. The framework sheds light on the following:

1. the problem to be solved;

2. the type of evaluation needed;

3. the matter to be evaluated;

4. the data collection methods and techniques to be used;

5. the timing.

ii.) Determining Objectives 
Evaluation is not conducted for nothing. The evaluator aims at reaching specific attainment which is the objective of the evaluation. Therefore, the objectives to be attained must be well determined before the evaluation is begun. In determining properly the objectives, the evaluator avoids the risk of making errors during the evaluation.

iii.)Appointing an Evaluator

Evaluation is not conducted without an evaluator. The evaluator must be appointed and be aware of his/her task. $\mathrm{He} / \mathrm{she}$ must be qualified for the evaluation work so as to come to valid and reliable results. In the case of this paper, there is no need to appoint an evaluator because the evaluation is made by me.

iv.) Drawing a Budget

Drawing a budget for an evaluation allows the evaluator to finish the work within the required period of time. This is to say that all financial means are available, the work progresses without much trouble. Therefore, the budget must be elaborated in a realistic way and be feasible before starting the evaluation.

\section{v.) Constructing a Plan}

An evaluation plan is an outline that guides the evaluator so as to help him/her not to follow all the steps without jumping some. The plan should be designed on the basis of objectives to be achieved.

\subsubsection{Implementation}

Implementation concerns data collection and evaluation management. The former answers the following questions:

1. what are appropriate data which are needed for evaluation?

2. where can such data be found?

3. how can they be collected?

The latter examines the validity, reliability, fairness, usefulness, credibility, and precision of the collected data so as to justify and support them.

\subsubsection{Analysis and Reporting}

After data are collected and managed, they need to be analyzed properly in order to come to valid and reliable results which must be communicated and serve for action and improvement.

Data can be analyzed by using either quantitative or qualitative methods depending on how these data were collected. When quantitative methods are used, the evaluator can use statistical methods or any other methods using numerical items. If the evaluator chooses to analyze data by using qualitative methods, he/she can use content analysis method or any others basing on interview and observation.

At the end of the analysis, the results are to be communicated to the target population or they can be just used for further researches as it is the case of the present article. This is to say that the evaluator can just report the results or exploit them in order to suggest possible improvements of the program.

\subsubsection{Action and Improvement}

The results of data analysis lead to decision-making and improvement. The decision is made either to stop the use of program or to maintain it with some changes. In case the program is stopped, there will be a need to find out another program and evaluate it before it is implemented. When the program is to be modified, the elements changed or modified have to be communicated to the target population.

\section{Language Performance Definition}

Reishaan and Taha [11] define performance as "a term used in the linguistic theory of transformational generative grammar, to refer to language seen as a set of specific utterances produced by native speakers, as encountered in a corpus". To put this clear, performance is an attainment achieved after a learning process. In other words, performance is an indicator that shows a satisfactory achievement of objectives or expected results.

Sonnentag and frees [12] distinguish two aspects of performance viz behavioral aspect and outcome aspect. For the former they write

The behavioral aspect refers to what an individual does in the work situation. It encompasses behaviors such as assembling parts of a car engine, selling personal computers, teaching basic reading skills to elementary school children, or performing heart surgery. Not every behavior is subsumed under the performance concept, but only behavior which is relevant for the organizational goals.

As far as the latter is concerned, they say that

the outcome aspect refers to the consequence or result of the individual's behavior ... Outcome aspects of performance depend also on factors other than the individual's behavior. For example, imagine a teacher who delivers a perfect reading lesson (behavioral aspect of performance), but one or two of his pupils nevertheless do not improve their reading skills because of their intellectual deficits (outcome aspect of performance).

Considering these two quotations from Sonnentag and Frese, one can remark that performance is based on both lecturer and students' efforts. On the one hand a lecturer has to design his/her course in the perspective of reaching realistic objectives. That is to say everything designed should aim to the expected results. Apart from the course, a lecturer's behavior should contribute to the achievement of the objectives.

On the other hand, for the students to come to performance, they should work hard in order to reach the goal for which they study. They should not only work for the grades but chiefly for their academic activities and occupational ones.

Performance can also be considered as the achievement of the Theory of Change which focuses on students' needs and lecturer's work in order to come to the expected outcome. For a better understanding, each of these components of the Theory of Change is discussed in the following lines.

\subsection{Students'Needs}

Teaching English to students dealing with veterinary medicine studies implies two kinds of purposes: academic 
and occupational purposes. These two purposes reflect the needs that students have. Therefore, the teaching of English in this field of veterinary medicine requires knowledge of learners' needs so as to design an appropriate course which must help students perform academic activities and become able to use English in their professional settings.

This lecturer's task seems to be difficult for an English lecturer who has less knowledge because he or she is not specialist in the field. As Ahmed [1] wrote that

Basturkmenis of the view that teachers may find themselves dealing with content in an occupation or subject of study that they themselves have little or no prior knowledge. Some may find themselves working alone in an on-site environment. They may find they have far less knowledge and experience in the subject than their learners".

To overcome such a difficulty, lecturer has to conduct investigations before he/she designs a teaching material to be given to students. In so doing there can be a hope to expect a change in students which makes them performant.

\subsection{Lecturer's Work}

Lecturer's work can bring students to performance if it is consisted of good teaching materials (based on students' needs), appropriate teaching strategies, high quality assessment, and good teaching/learning environment. Good teaching materials (materials designed on the basis of the results of investigations) attract students' attentions since the course content meets their needs. Students realize that the lecture helps them perform academic activities and become competent and performant for the professional business. If the teaching material does not meet students' needs or interests, the learning becomes less interesting for them, and as consequence they neglect it. In this case, they cannot attain the expected performance. Therefore, good teaching materials constitute the first step to students' performance.

Apart from good teaching materials, appropriate teaching strategies are required. One can have good teaching materials and fail in teaching because of inappropriate methods and techniques. To get good students' performance, Input-based strategies, Input-output strategies and Output-based strategies are proposed. The first strategy consists in providing students with materials aiming to reach the course objective as Ahmed [1] argues that "teachers should aim to direct students' attention to the targeted forms or features in the input so that the students will develop explicit knowledge of them". The second strategy is students' feedback. Ahmed [1] speaking of Input-output strategy, he states that

in this strategy, the focus is on students acquiring explicit knowledge of preselected language items. The teacher selects specific items (target linguistic forms or features) as the focus of instruction. The items are presented or highlighted by the teacher. This is followed by some form of practice activity in which the students produce the items.

Students must practice what has been taught to them in order to reach performance. For them to put what they have learnt into practice, the lecturer should give them that opportunity. The third strategy concerns students' abilities and courage to use what they have learnt in the real target context. Ahmed [1] stipulates that "students are placed in situations that require them to perform production tasks (to produce output) at the outset of a lesson or activity". This is to say the lecturer has to bring his/her students to real life context so as to give opportunity to students to perform what they have learned in the auditorium.

When good teaching strategies are used, it is supposed that students have learnt and are capable of performance. To make sure that students have mastered the teaching materials, the lecturer has to assess his/her students. The assessment should be based on the teaching objectives. When assessment is well set, the students are aware of the level they have reached and their abilities to perform tasks using the target language. All these activities should be done in a good teaching/learning environment. Auditorium should offer a comfortable setting to both lecturer and students.

\subsection{Expected Outcome}

Performance is much concerned with the expected outcome at the end of a course or program. In language teaching/learning, the outcome is viewed through the four skills namely speaking skills, listening skills, reading skills, and writing skills. If at the end of course or program students are able to speak, listen, read and write properly by using English, one can conclude that the lecturer's work has reached a good outcome.

A good outcome presents changes in students as far as their speeches, behavior, action, attitude, understanding are concerned. Woodhouse [13] adds that "Outcomes could reflect change in: Policy, rules, regulations, Circumstances for organizations, groups or individuals Status -health status, behavior, skills or competencies, ability to function Knowledge or attitude Prevention Activities -process measures".

\section{Speaking Performance Evaluation}

\subsection{Questionnaire}

The total number of the Third-Year Vet Med Students is 33 , but those who were evaluated are 30 for the questionnaire and 29 for the achievement and performance tests. Here below are the questionnaire and the tests.

1) Are you able to perform any presentation in English?

Yes $\square$ Yes but with mistakes $\square$ No $\square$

1. $34 \%$ of the Third-Year Students say that they are able to perform any presentation in English.

2. $24 \%$ of the Third-Year Students say that they can perform with mistakes any presentation in English.

3. $41 \%$ of the Third-Year Students say that they cannot perform any presentation in English.

2) Can you converse in English with other veterinarians who speak English?

Yes $\square \quad$ Yes but not well $\square \quad$ No $\square$ 
1. $17 \%$ of the Third-Year Students say that they can converse in English with other veterinarians who speak English.

2. $45 \%$ of the Third-Year Students say that they can hardly converse in English with other veterinarians who speak English.

3. $38 \%$ of the Third-Year Students say that they cannot converse in English with other veterinarians who speak English.

3) Can you listen to someone speaking English?

Yes $\square$ Yes but not well $\square$ No $\square$

1. $45 \%$ of the Third-Year Students say that they can listen to someone speaking English.

2. $52 \%$ of the Third-Year Students say that they can hardly listen to someone speaking English.

3. 3\% of the Third-Year Students say that they cannot listen to someone speaking English.

4) Can you hold a debate in English?

Yes $\square$ Yes but not well $\square$ No $\square$

1. $38 \%$ of the Third-Year Students say that they can hold a debate in English.

2. 38\% of the Third-Year Students say that they can hardly hold a debate in English.

3. $24 \%$ of the Third-Year Students say that they cannot hold a debate in English.

\subsection{Achievement and Performance Test}

1) Perform a 3 minute-presentation about whatever you know in veterinary medicine.

1. $10 \%$ of the Third-Year Students perform well a 3 minute-presentation about whatever they know in veterinary medicine.

2. $40 \%$ of the Third-Year Students perform badly a 3 minute-presentation about whatever they know in veterinary medicine.

3. $50 \%$ of the Third-Year Students perform very badly a 3 minute-presentation about whatever they know in veterinary medicine.

2) Read loudly this short text and say what you understand.

1. $17 \%$ of the Third-Year Students say well the content of an English text.

2. $23 \%$ of the Third-Year Students say badly the content of an English text.

3. $60 \%$ of the Third-Year Students say very badly the content of an English text.

\section{Observation of Teaching Process}

Since teaching is the input from which performance can be evaluated, this section describes the way English is taught to students in Veterinary Department so as to present the picture of English lectures. The lecture starts by greetings and asking questions generally from the lecturer. Then the lecturer asks students one after another to read the material in the handout. At the end of each sequence, the lecturer explains the content to students. After fifteen hours, the quiz is announced by the lecturer in order to assess students who have to read the material taught so as to sit for the quiz. Assignments and exam are parts of the assessment.

Now, let us discuss each of the important activities involved in the teaching process of English in Veterinary Medicine Department at the University of Kinshasa. The activities are reading, lecturer's explanation, students' questions, lecturer's answers, lecturer's questions, students' answers, quiz, and assignment.

\subsection{Reading}

Students read loudly and the lecturer corrects mispronunciation mistakes and explains the content of sentences. While one student is reading, other students are supposed to read silently the same text. But it has been observed that some students did not read the text or they did not locate the places being read because of their absentmindedness.

It has been observed that only few students could be courageous to read whereas many students did not like to be appointed for reading because they were ashamed of making mispronunciation mistakes. Some technical words were difficult to be read by students who asked for help.

As the reading was difficult, students were uncomfortable and lost their attention. In the case reading was difficult; the lecturer could read and explained what needed to be explained. Students gave the impression that they hardly caught meaning of words. This is why some of them asked questions so that the lecturer explained, translated into French, and repeat the concerned words.

The other fact relating to reading was that some words were too difficult to understand to the extent that even the translation could not solve the problem because the French equivalent word was also unknown by the students. In the case of this dilemma, the lecturer used to ask students to go and check either in the dictionary or to search on the internet.

Considering all is said above, one can notice that, at this stage of reading, students are supposed to have known before how to read, and the lecturer's role is just to correct mistakes. It is clear that students are not taught systematically how to read a scientific text and comprehend it. That is to say, an appropriate way of reading and techniques of reading are not taught to students.

\subsection{Lecturer's Explanation}

The lecturer's explanation is the most important activity that transmits knowledge to students. It is important to point out here that some words did not need any explanations because the students knew them before. This is the case of materials related to greetings and introduction. It has been noticed that the lecturer's explanation consisted in providing students with grammatical structures, illustrations, and meaning of words.

\subsection{Grammatical Structures}

The explanation based on grammatical structures is 
noticed mainly in the first part of the course namely general English. The lecturer described the sentence elements and their positions within a sentence. Apart from the sentence elements, the parts of speech were also explained by insisting on their positions in a sentence.

This way of explaining seems to be good in the way that students come to discover meanings of words or sentences through grammatical structures. But it does not provide students with strategies to grasp contextual meaning. Students remain stuck to grammar rules and lexical meaning only. This is too dangerous since it affects students' reading comprehension because students cannot understand beyond denotation meaning.

\subsection{Illustrations}

To explain some words, the lecturer used illustrations to explain some words such as names of animals and clinical equipment. Some of the illustrations were found in the handout. For students who had no handout, it was difficult for them to understand new words. Another important fact which was noticed while the lecturer was illustrating was that some students did not care about those illustrations.

Providing students with illustration so as to help them understand is one of good strategies in teaching vocabulary. But much attention should be paid to the way of illustrating. Let us consider the illustration of colors in the handout; all colors were black because the handout was a photocopy. As the consequence, students could read the word 'red' but its illustration was black. In this case, they cannot distinguish black from red.

\subsection{Meaning of Words}

The lecturer had to provide students with meaning of technical words that were found in the texts. Unfortunately meaning of some words was not easy to be grasped by students. Students used to jot down the meaning of new words in French for a further remembrance.

As it can be noticed, the students hardly use new lexical items in their own sentences so as to internalize their meanings. Since they do not internalize meanings of new words, they easily forget them.

\subsection{Students' Questions}

Students' questions based mainly on word translations and explanations of some sentences. The students wanted their lecturer to translate English words found in the handout into French so as to grasp meaning of those words. They also wanted to get explanations of sentences containing new difficult words. Most of the time, students could not or could slightly understand explanations given in English.

The fact of not understanding explanation given in English shows clearly that the Third-Year Students in Veterinary Medicine Department did not develop, as it is expected, the listening skills. This is justified by the fact that they were not given any listening exercise.

\subsection{Lecturer's Answezrs}

Students ask questions to the lecturer, and the latter answers them by translating some words from English into French (the language that students speak and understand easily) so as to enable students grasp meaning of words. As far as explanation of sentences is concerned, the lecturer explains by using illustrations, actions, and gestures.

This way of answering is good, but it would be better if the lecturer could ask other students to answer questions so as to make all students participate to the lecture. It was remarked that students could not debate or discuss among themselves in English. This is one of the reasons that students did not develop speaking skills as stated in the objectives of the course.

\subsection{Lecturer's Questions}

Questions are not only asked by the students; the lecturer used also to ask questions to the students. The lecturer's questions were mainly based on reading comprehension and filling in gaps. That is, the lecturer asks students to tell what they have understood after the reading of the text. Or, students are asked to fill in blank spaces with pronouns or adjectives.

The lecturer asked good questions, but students hardly answered them because of two reasons: some did not understand whereas the other students understood, but they could not speak. This fact reveals that students are not prepared to answer questions. They lack useful and appropriate expressions that can permit them respond to questions.

\subsection{Students' Answers}

Students hardly answered the lecturer's questions. That is to say, the students could have got answers, but they failed to utter them properly because of their difficulties to speak English. Most of the time, they answered by mixing both English and French.

The students' answers reveal that, the Third-Year Vet Med Students are incapable of speaking English after they have learned it for three years. They did not develop the language skills mentioned in the course handout.

\subsection{Quiz and Assignment}

\section{a. Quiz}

The academic instructions stipulate that a lecturer should set a quiz after he/she has taught for fifteen hours. Automatically, this instruction is incorporated in the methodology of the course. As far as the English course in the Third-Year is concerned, the lecturer set a quiz so as to assess the students' knowledge. Each student had to work or answer the questions without help or collaboration with the other students.

\section{b. Assignment}

The lecturer has planned exercises for assignment at the end of the students' handout. It means that the assignment is 
given at the end of the course. The exercise for assignment differ from the quiz in that students can work together so as to share ideas and knowledge. Furthermore, students can work with help from other experienced people or students from other department such as English Department.

\section{Discussion}

The Third-Year vet Med Students cannot speak fluently and accurately because they are taught communicatively. That is, students do not have any speaking activity relating to making presentations, debates, and discussions which can enable them to develop oral skills. The lecturer in charge of teaching English is recommended to teach English by training students in making presentations, debating, and holding discussion. Here below each of these activities is discussed and shown how it can be held.

\subsection{Making Presentation}

Making presentation does not consist only in asking students to perform presentations. It also consists in teaching how to make a scientific presentation (in the domain of veterinary medicine) by providing students with appropriate tips and expressions. In other words, it is important to teach how to make presentations before asking students to perform them.

\subsection{Holding Debates}

As it is said above regarding to making presentation, students should also be initiated in holding debate in the classroom during lectures. This is the lecturer's responsibility to provide students with required tips and expressions to be followed or used in scientific debates. If students are well trained in holding debates, they develop easily the four language skills because in debating students speak, listen, write (questions, notes, etc), and read (topics, extracts, and questions). Holding different debates on several realistic topics (within the field of veterinary medicine) in the classroom, students become familiar with the language as consequence their language skills get highly developed. When the four language skills are highly developed, students become performant in English and able to use it professional settings and elsewhere.

\subsection{Discussions}

Discussions should not be confused with debates although they have in common several features. Here, a discussion is understood as a share of ideas or contribution that each student suggests in problem solving. Discussion also allows students to share their points of view during lectures as Carrasco and Irribarra say that "The open classroom discussion scores indicate whether students can discuss, during regular lessons, ...". For instance, the lecturer should not consider himself/herself to be the only knower in the classroom. Some students' questions should be discussed and answered by other students. In so-doing, students share their ideas and enjoy the learning.
Furthermore, the lecturer can design different topics for discussion in the classroom or ask students to raise a question on a given matter or phenomenon in the field of veterinary medicine so as to share ideas and experiences.

\section{Conclusion}

This paper has been investigating into the reasons why the Third-Year Vet Med Students in Veterinary Medicine Department are not performant in oral English after they have learnt English for three years.

To reach this aim, a questionnaire, achievement and performance tests, and observation of teaching process were used during the investigation. The results and their interpretation have brought to conclude that the Third-Year Students in Veterinary Medicine at the University of Kinshasa are not performant in oral English because they are not taught communicatively. That is to say that these students are not exposed to activities such as making presentations, holding debates, and discussions. Therefore, this paper has contributed by recommending to the lecturer in charge of teaching English these activities and how they should be held. Furthermore, students should participate actively to lectures and do what is recommended by the lecturer as Kapur [14] argues that "The determinants of academic performance of the students include, class participation, class assignments, home-work assignments, tests, examinations, and participation in competitions or other events".

\section{References}

[1] Ahmed, M. K. (2014). The ESP Teacher: Issues, Tasks and Challenges in "English for Specific Purposes World". ISSN 1682-3257, www.esp-world.info, Issue 42, Vol. 15.

[2] Basturkmen, H. (2006). Ideas and Options in English for Specific Purposes. London: Lawrence Erlbaum Associates.

[3] Boothroyd, R. A. (2018). Process and Outcome Evaluation Approaches. South Florida: University of South Florida.

[4] Cambridge English. (2016). Principles of Good Practice. Research and innovation in language learning and assessment. Cambridge: Cambridge University Press.

[5] Derbinski, N. And Reinhardt, T. (2017). The Evaluation Process in 10 Steps - a Guideline. Berlin: Brotfür die Welt.

[6] Desheng, C. And Varghese, A. (2013). "Testing and Evaluation of Language Skills" in OSR Journal of Research \& Method in Education. Vol. 1. Issue 2. pp. 31-33 online.

[7] Gertler, P. J. et al. (2016). Impact Evaluation in Practice. Second Edition. Washington, DC: International Bank for Reconstruction and Development / The World Bank.

[8] Ghazali, N. H. M. (2016). A Reliability and Validity of an Instrument to Evaluate the School-Based Assessment System: A Pilot Study in"International Journal of Evaluation and Research in Education (IJERE)". Vol.5, No.2, June, pp. 148 157 ISSN: 2252-8822. 
[9] KEY, T. S. (2014). "Evaluation: Types and Characteristicsof a Good Evaluation Process" in Child Development and Pedagogy. Online.

[10] Peersman, G. (2014). Overview: Data Collection and Analysis Methods in Impact Evaluation in "UNICEF Office of Research". Florence: UNICEF.

[11] Reishaan, A. K. and Taha, W. A. (2008). The Relationship between Competence and Performance Towards a Comprehensive TG Grammar. Kufa: University of KufaCollege of Art.

[12] Sonnentag, S. And Frese, M. (2001). Performance Concepts and Performance Theory. Germany: University of Konstanz.
[13] Woodhouse, L. D. (2007). Outcome measures for assessing progress of meeting PHP or SPH Goals. Washington, DC: CEPH Technical Assistance Session.

[14] Kapur, R. (2018). Factors Influencing the Students Academic Performance in Secondary Schools in India. Delhi: University of Delhi.

[15] Carrasco D. And Irribarra, T. D. (2018) The Role of Classroom Discussion. In: Sandoval-Hernández A., Isac M., Miranda D. (eds) Teaching Tolerance in a Globalized World. IEA Research for Education (A Series of In-depth Analyses Based on Data of the International Association for the Evaluation of Educational Achievement (IEA)), vol 4. Springer, Cham. 